\title{
Resolução de um caso de prótese parcial removível utilizando o método de transferência de planos-guias
}

\author{
Resolution of a case of removable partial denture through the transfer \\ of guiding planes
}

\author{
Célia Cristina Fornaziero* \\ Cassiano Ricardo Turino Ferreira* \\ Maurício Sella **
}

FORNAZIERO, C. C; FERREIRA, C. R. T.; SELLA, M. Resolução de um Caso de Prótese Parcial Removível Utilizando o Método de Transparência de Planos-guias. Semina, Londrina, v. 18, ed. especial, p. 78 - 82, fev. 1997.

RESUMO: Uma Prótese Parcial Removivel deverá entrar e sair de posição sem transmitir forças de pressão aos dentes, principalmente os que se situam imediatamente após os espaços protéticos; para tal podemos utilizar planos-guias. Este trabalho tem por objetivo aplicar uma técnica prática e segura, usando um dispositivo que permite a transferência de direção de inserção preparada no modelo de estudo, através do delineador, para a boca do paciente. Os autores confeccionaram uma prótese parcial removivel inferior classe III de Kennedy, através do preparo de planos-guias. Concluímos que essa técnica possibilita um bom controle e visualização do futuro plano-guia por parte do profissional.

PALAVRAS-CHAVE: Preparo de Boca; Apoios Dentários; Prótese Parcial Removivel; Plano Guia.

ABSTRACT: A removable partial denture must enter and leave its position without transmitting pressure forces to the teeth, specially to the ones placed immediately after prosthetics spaces; for that we may use guiding planes. The objective of this study is to apply a practical and safe technique, using a device that allows the transfer of direction of insertion prepared on the study model, through the delineator, to the patient s mouth. The authors built a Kennedy's class III inferior removable partial denture, through the making of guiding planes. We came to the conclusion that this technique allows a good control and visualization of the future guide plane by the professional.

KEY WORDS: Mouth adjustment; Tooth support; Removable partial denture; guiding planes.

\footnotetext{
* Autor: Aluno do $5^{\circ}$ ano de Graduação em Odontologia da Universidade Estadual de Londrina.

*: Orientador: Mestre em Prótese, Professor Adjunto de Prótese Dentária da Universidade Estadual de Londrina/Centro de Ciências da Saúde- rua Pernambuco, 540

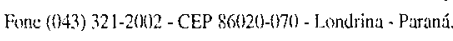




\section{INTRODUÇÃO E REVISÃO DE LITERATURA}

Para a confecção de uma prótese parcial removível a qual é sabido que é indicada em muitas situações de pacientes parcialmente edentados, é necessário que se faça um preparo bucal, sendo este de fundamental importância para o sucesso do tratamento preconizado.

Segundo McCRACKEN 1994, as preparações bucais, mais do que qualquer outro fator isolado, contribuem para a filosofia de que a prótese prescrita deve não só substituir o que está faltando, mas também preservar o que resta que parece ser de maior importância. A preparação bucal segue o diagnóstico preliminar e a elaboração de um plano de tratamento ou planejamento. TAMAKI 1982, preconiza que o preparo bucal, também denominado preparo prévio inclui dois tipos de procedimentos: tratamento clínico geral e tratamento ou preparo dos dentes suportes. Dentre as prepações dos dentes suportes, destacar-se-á o preparo de planos-guias, procedimento que apesar de sua extrema importância na inserção e remoção da prótese parcial removível é, às vezes, negligenciado por profissionais da área.

Segundo ZANETTI 1986, HENDERSON; STEFFEL 1976, definiram planos-guias como duas ou mais áreas planas preparadas nas superfícies axiais dos dentes suportes ou de restaurações metálicas, paralelas entre si e ao eixo de inserção e remoção da prótese. Henderson; Steffel 1976, apresentam as seguintes funções de planosguias: a) proporcionar um uníco sentido de direção para a inserção e remoção da prótese segundo o eixo de inserção pré-determinado.

b) eliminar forças tangenciais nocivas aos dentes suportes durante os atos de inserção e remoção da prótese.

c) proporcionar o princípio biomecânico da reciprocidade, através do braço de oposição do grampo, quando a ponta ativa do braço de retenção translada a linha guia equatorial do dente suporte.

d) impedir a retenção ou impaç̧ão de alimentos entre os dentes suportes e o conector menor ou selas da prótese.

Segundo Magalhães 1984, os planos-guias também funcionam como auxiliares na retenção da prótese, pois as superfícies, planas e rígidas dos conectores menores e braços de oposição dos grampos estando em íntimo contato com as superfícies verticais e paralelas entre si dos dentes suportes, promovem uma retenção auxiliar à mesma.

Holt 1981, coloca que os planos-guias também auxiliam na estabilidade contra movimentos horizontais a que as próteses estão sujeitas, além de promoverem maior estética. BURSE 1977, indica a confeç̧ão de planosguias para transferir a linha equatorial mais gengivalmente, aumentando a área expulsiva para aplicar o braço de oposição do grampo, em dentes cuja linha equatorial se situa muito oclusalmente em relação à coroa do dente. Também em dentes que apresentam grande ângulo morto, ou seja, área entre dente e corpo do grampo, para facilitar o plano de inserção da prótese.

Quanto ao preparo do plano-guia, STERN 1975, orienta que no sentido ocluso-gengival, o plano guia deve ser igual à distância percorrida pela ponta ativa do braço de retenção, desde o instante em que toca o dente acima da linha guia equatorial até o o alojamento final da prótese, isto é, deve ser igual ao campo de ação da ponta ativa do braço de retenção.

Henderson; Steffel 1976, preconizam uma técnica para o preparo de planos-guias através da confecção das guias de transferência em restaurações metálicas fundidas, durante a fase de enceramento. Desgasta a cera até obter os planos-guias, depois faz a inclusão e fundição. Reposiciona as coroas nos troquéis para fresagem e acabamento.

ZANETTI 1986, preconiza a construção de coroasguias de transferências. Faz o desgaste dos dentes suportes em gesso, recobrindo-os com cera para fundição e desgasta a cera até que os planos-guias previamente obtidos sejam evidenciados. Remoção dos padrões de cera, inclusão em revestimento e fundição. Após a fundição a coroa-guia passa por tratamento térmico endurecedor. Cimentação das coroas-guias dos dentes suportes na boca do paciente, remoção das superfícies de esmalte salientes às superfícies axiais das coroas-guias, acabamento, polimento e aplicação tópica de flúor.

MAGALHÃES et al. 1984, indicam a confecção da guia de transferência em resina acrílica térmica ou quimicamente ativada. Os autores preparam planos-guias no modelo, desenham as futuras guias de transferência $\mathrm{c}$ as confeccionam em resina acrílica através da polimerização da resina. Utilizando o delineador, desgasta-se a resina até que fíque paralela ao plano-guia 
previamente obtido.

\section{PROPOSIÇÃO}

Este trabalho tem por objetivo aplicar uma técnica usando um dispositivo que permite a transferência da direção de inserção, preparada no modelo de estudo para a boca do paciente. Esse dispositivo é chamado por FIORI 1993, de guia de transferência da direção de inserção.

\section{MATERAIIS ERTETODOS}

Após a seloção do paciente, atravós de moldagens com algatato, foram obtidos os modelos de estudo. Segmno as chas prelminares de exames to paciento e plancjaneno da estudo, hixamos o modelo do arco que

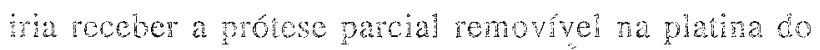

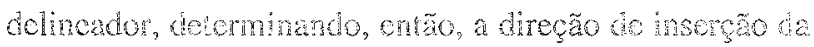
pótese parcial romovivet.

Para detemina o plano da direção de insercáda

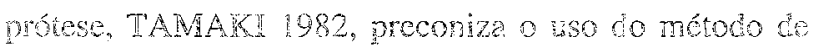
Roach ou dos tres pontos de referencia ro mocelo sendo un na parte untorion e os ontros dois na parte posterion,

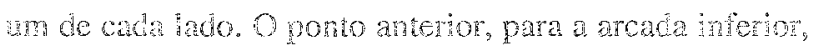
localiza-se entre as faces mesiais dos incisivos centrais, na borda incisal. Os pontos posreriores, em próteses incercaladas, fosseda marginal mesial do primeino dente depois do esparo protético.

A seguir, delineamos o modelo locanizando o equador protetico dos dentes suportes principars, ou sejal, delimiando suas areas retentvas e expullsiyas. Com os modolos anda fixados na platia do delimeador, deteminumos as arcas a serem desgastadas: Inguais e proximo-mesiais los primeros molares, sobre as quais preparamos os planos-guia. Sobre essas áreas form confecoionalas guies de resima acrilica ativada quimicamente, recobrindo toda superficie lingual, proximal, oclusal e a face vestibular ate a linha equatoria:

Segundo MAGALHÃES ê al 1984, a espessura da guia deverá ser em torno de $5 \mathrm{~mm}$, formando uma convexidade para ser desgastada. As áreas axiais da guia acrílica, correspondentes às regiões onde foram preparados os planos-guias foram desgastadas com ponta diamantada n.720 para peça de mão, a qual é acoplada ao delineador por um dispositivo que o acompanha.

Os desgastes foram executados na superfície da resina até atingir o dente suporte. Concinuamos a desgastar a resina até que esta ficasse paralela ao plano-guia obtido no modelo de estudo, com a largura e a profundidace que descjávamos instituir nos dentes naturais do pacicrte 0 dentro do limite da espessura do esmalte conseguiu-se una área adequada para a obtenção do plano-guia (fig. : e).

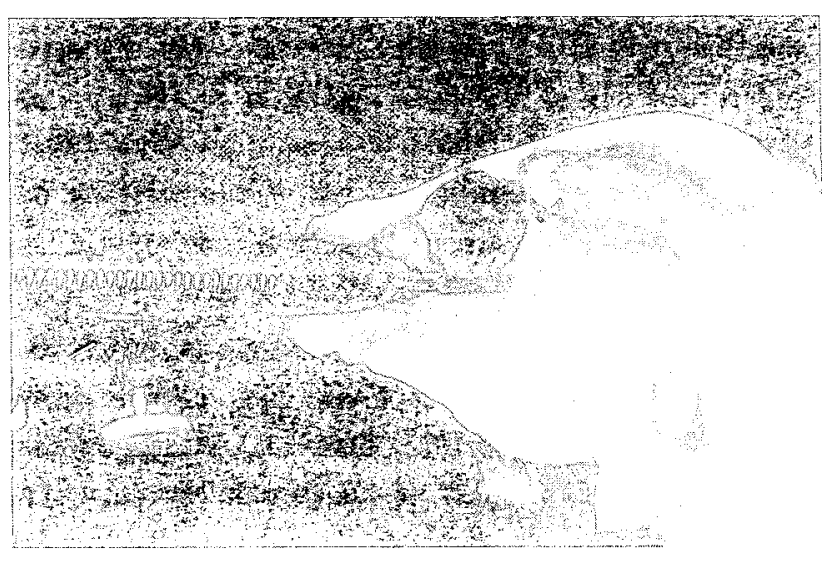

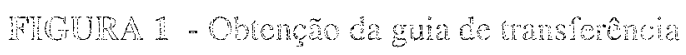

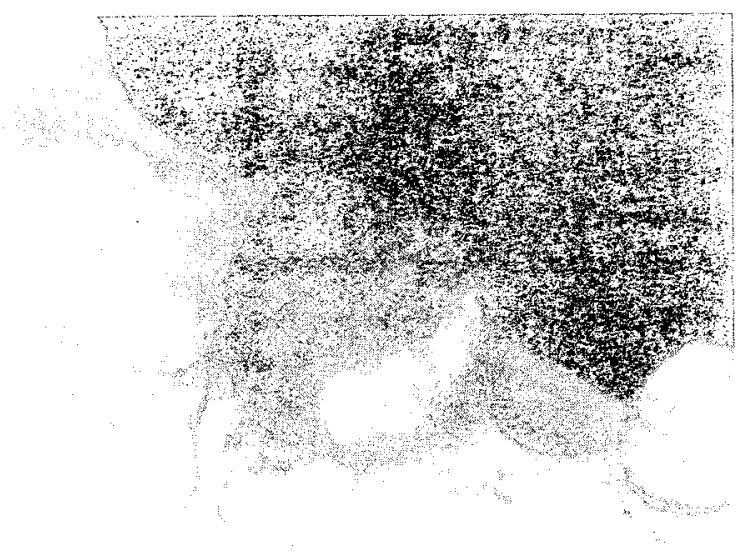

FIGURA 2 - Guia de transferencia pronta no modelo 
A guia de transferência foi removida do modelo e levada à boca do paciente, ficando exposta a parede de esmalte a ser desgastada, ao mesmo tempo guiando a quantidade de desgaste a ser executado. O desgaste em esmalte foi feito com ponta diamantada tronco-cônica $n$. 2136, a superfícic obtida apresentou-se planificada e lisa (fig. 3).

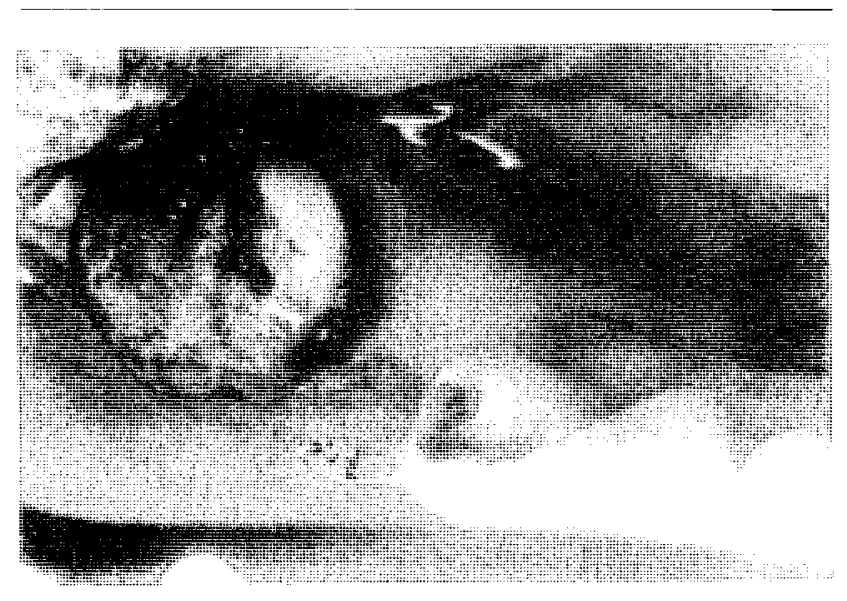

FIGURA 3 -Guia levada à boca

As superfícies desgastadas foram polidas com discos de lixa, borracha abrasiva e escova de Robinson e por último prolegidas com aplicação tópica de flúor. Após o polimento, obteve-se o modelo de trabalho através de moldagem em alginato; vazou-se em gesso pedra especial, sobre o qual foi confeccionada a prótese (fig. 4).

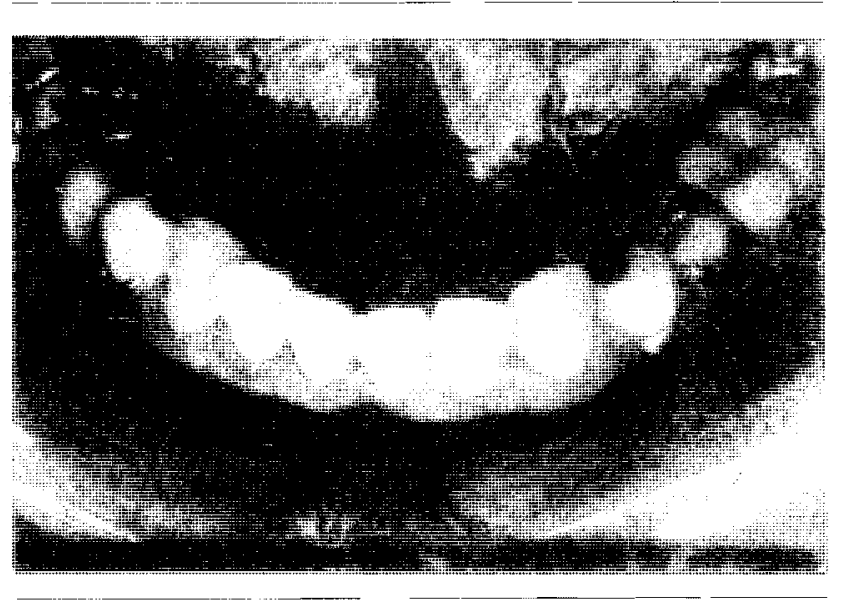

FIGURA 4 - Resultado final

\section{DISCUSSÃO}

HARROP; JAVID 1976, concordam que as próteses parciais removíveis apresentam alguns problemas no planejamento dos grampos e nichos oclusais que podem conduzir à violação dos princípios biológicos, causando reabsorção óssea e mobilidade dentária. Sendo que para impedir esses efeitos confeccionamos os planos-guias.

ZANETTI 1986, coloca que o preparo de planosguias através de coroas-guias de transferência apresenta a grande vantagem de ser uma lécnica simples e segura, limitando a quantidade de esmalte a ser removida. Praticamente não há possibiliơade de crro na confecção dos planos-guias, pois as coroas são cimentadas no dente suporte.

HENDERSON; STEFFEL 1976, também indicamo preparo dos planos-guias em coroas metálicas fundiclas. MAGALHAES et al . 1984, preconiza o uso de transterências em resina acrílica, pois além de seu baixo custo, é uma técnica de fácil execução c utilização: os planos-guias obtidos no modelo de estudo são facilmente transportados na mesma inclinação para a boca do paciente.

\section{CONCLUSAOO}

Para análise da técnica de plano-guia descrita neste trabalho, concluímos que a técnica da confecção da guia de transterência en resina acrílica ativada quimicamente adaplada ao dente é de grande praticidade e de fácil exccuça, além de sen baixo custo. Essa técnica possibilita um bon controle e visualização do fubro plano-guia, por parte do profissional 


\section{REFERÊNCIAS BIBLIOGRÁFICAS}

1. BURSE, A.B. Preparo do paciente e da boca para receberem próteses parciais removíveis. Ars CVRANDI em Odontologia, Sao Paulo, v.4, n.9, p. 28-32, Dez. 1977.

2. FIORI, S.R. Atlas de Prótese parcial removível. São Paulo: Pancast, 1993. cap:2 Biomecânica de inserção e de retirada das próteses parciais removíveis, p. 53-78.

3. HARROP, J. ; JAVID, N. Reciprocal arms of direct retainers in removable parcial dentures. I. Canad Dent Assn, v.42, n.4, p. 208-11, 1976.

4. HENDERSON, D. ; STEFFEL, V. L. Prótesis parcial removible según McCracken. Buenos Aires: Mundi, 1976, p. 208-11.

5. HOLT, J. E. Guiding planes: when and where. The Joumal of Prosthetic Dencistry v. 46, n.1 p. 4-6, Jul.1981.

6. MAGALHÃES, O. et. al. Prótese parcial removível. Un método prático de transferência dos planos-guias, obtidos nos modelos de estudo através do delineador, para a boca do paciente. Rev. Paul. Cirurg. Dent., v.38, n.6, p. 394-406, Nov/Dez. 1984.

7. MCCRACKEN, J. W. Prótese parcial removível de McCracken. São Paulo: Artes Médicas, 1994. cap 10: Delineamento, p.125-39.

8. STERN, W. J. Guiding planes in clasp reciprocation and retention. J. Prosthet Dent v. 34, n.4, p. 40814, Oct. 1975 .

9. TAMAKI, T. Prótese parcial fixa e removível. _São Paulo: Sarvier, 1982. cap 20: Delineador, planejamento, desenho e preparo da boca, p.191205.

10. ZANETTI, A. L. ; FRONER, E. E. Planos-guias. Obtenção através de coroas-guias de transferências. - Rev. Ass. Paul. Cirurg. Dent., v.40, n.30, p.219-23, Mai/Jun. 1986.
* Trabaiho apresentado nos seguintes eventos científicos:

- II Ciclo Acadêmico Odontológico - 20 de outubro de 1995.

- I Jornada Odontológica de Londrina - 06 a 08 de junho de 1996. 